\title{
Association between perioperative normal saline and delayed graft function in deceased-donor kidney transplantation: a retrospective observational study Association entre l'administration périopératoire de soluté salé isotonique et le retard de reprise de fonction du greffon après transplantation rénale à partir de donneurs cadavériques : une étude observationnelle rétrospective
}

\author{
Nicolas Nesseler • Alexandre Rached • James T. Ross • Yoann Launey • Cécile Vigneau • \\ Karim Bensalah • Hélène Beloeil • Yannick Mallédant • Ronan Garlantezec • \\ Philippe Seguin
}

Received: 3 July 2019/Revised: 7 October 2019/Accepted: 13 October 2019/Published online: 27 January 2020

(C) Canadian Anesthesiologists' Society 2020

\begin{abstract}
Purpose Isotonic 0.9\% sodium chloride (normal saline; NS) solution use is common, but its high chloride content has been shown to contribute to acid-base disturbances and acute kidney injury (AKI). As kidney transplant recipients are at high risk of postoperative AKI and renal replacement therapy, we aimed to evaluate the impact of perioperative NS administration on graft function after kidney transplantation.
\end{abstract}

This article is accompanied by an editorial. Please see Can J Anesth 2020; 67: this issue.

Presentation: Preliminary data for this study were presented as a poster presentation at the European Society of Anaesthesiology (ESA) Euroanesthesia, 28-30 May 2016, London, United Kingdom.

Electronic supplementary material The online version of this article (https://doi.org/10.1007/s12630-020-01577-9) contains supplementary material, which is available to authorized users.

N. Nesseler $(\bowtie) \cdot H$. Beloeil · P. Seguin

Department of Anesthesia and Critical Care, Pontchaillou,

University Hospital of Rennes, Rennes, France

e-mail: nicolas.nesseler@chu-rennes.fr

Univ Rennes, CHU de Rennes, Inra, Inserm, Institut

NUMECAN, Rennes, France

Univ Rennes, CHU Rennes (Centre d'Investigation Clinique de

Rennes), Rennes, France
Methods All adult patients undergoing deceased-donor kidney transplantation between January 2010 and December 2014 at the Rennes University Hospital were included. Logistic regression models were constructed to evaluate the association of hyperchloremia and hyperchloremic acidosis on delayed graft function $(D G F)$, defined as the need for renal replacement therapy within the first week after transplantation.

Results Three hundred and fifty-nine patients were included, 20\% developed DGF. The mean (standard deviation) volume of $N S$ infused in the operating room and in the standard postoperative intensive care unit stay was 4,832 (2,242) $\mathrm{mL}$. In the first 24 postoperative hours, $11 \%$ of patients developed hyperchloremia and $11 \%$ developed hyperchloremic acidosis. These outcomes were not associated with significantly higher total volumes of NS administration or with DGF. In contrast, multivariable analysis showed that cold ischemia time, donor terminal

\footnotetext{
A. Rached

Department of Anesthesia and Critical Care, Pontchaillou,

University Hospital of Rennes, Rennes, France

J. T. Ross

Department of Surgery, University of California, San Francisco,

CA, USA

Y. Launey · Y. Mallédant

Department of Anesthesia and Critical Care, Pontchaillou,

University Hospital of Rennes, Rennes, France
} 
creatinine, and perioperative NS volume were all independent predictors of DGF.

Conclusion Perioperative NS infusion volume was associated with DGF in deceased-donor kidney transplant recipients. Conversely, postoperative hyperchloremia and hyperchloremic acidosis were not associated with an increased risk of DGF, suggesting other mechanisms than a chloride effect.

\section{Résumé}

Objectif Le soluté salé isotonique ( $\mathrm{NaCl}$ ) 0,9\% est communément utilisé comme solution de remplissage. Sa teneur élevée en chlore contribuerait à la genèse de perturbations acido-basiques avec un risque d'insuffisance rénale aigüe (IRA). Les patients transplantés rénaux constituent une population à risque accru d'IRA et d'épuration extra-rénale (EER) postopératoires. Notre objectif était d'évaluer l'impact de l'administration périopératoire de $\mathrm{NaCl}$ 0,9\% sur la reprise de fonction du greffon.

Méthodes Tous les patients adultes ayant bénéficié d'une transplantation rénale issue de donneurs cadavériques au Centre hospitalier universitaire de Rennes, France entre 2010 et 2014 étaient inclus. Des modèles de régression logistique ont permis d'évaluer l'impact de l'acidose hyperchlorémique et de l'hyperchlorémie sur le retard de reprise de fonction du greffon (RRFG) défini par le recours à l'EER dans la semaine qui suivait la transplantation.

Résultats Sur les trois cent cinquante-neuf patients inclus, $20 \%$ ont présenté un RRFG. Le volume moyen (écart type) de $\mathrm{NaCl}$ 0,9\% périopératoire administré était de $4832 \pm$ $2242 \mathrm{~mL}$. Dans les $24 \mathrm{~h}$ postopératoires, $11 \%$ des patients ont présenté une acidose hyperchlorémique et $11 \%$ une hyperchlorémie, sans qu'ilsaient reçu significativement plus de $\mathrm{NaCl}$ 0,9\%. Le temps d'ischémie froide, la créatinine plasmatique terminale du donneur et le volume de $\mathrm{NaCl}$ 0,9 \% périopératoire sont apparus comme facteurs de risque indépendants de RRFG dans une analyse

Univ Rennes, CHU de Rennes, Inra, Inserm, Institut NUMECAN, Rennes, France

\section{Vigneau}

Department of Nephrology, Pontchaillou, University Hospital of Rennes, Rennes, France

K. Bensalah

Department of Urology, Pontchaillou, University Hospital of Rennes, Rennes, France

R. Garlantezec

Univ Rennes, CHU de Rennes, Irset (Institut de recherche en santé, environnement et travail), Rennes, France

Department of Public Health and Epidemiology, Pontchaillou, University Hospital of Rennes, Rennes, France multivariée. À l'inverse, l'acidose hyperchlorémique et l'hyperchlorémie postopératoires n'étaient pas associées à un RRFG.

Conclusion $\mathrm{Au}$ contraire du volume de $\mathrm{NaCl} 0,9 \%$ périopératoire administré, l'acidose hyperchlorémique et l'hyperchlorémie postopératoires n'étaient pas associées à un risque accru de RRFG après transplantation rénale issue de donneurs cadavériques, suggérant un mécanisme autre que la toxicité du chlore.

Isotonic $0.9 \%$ sodium chloride or normal saline (NS) solution is a common resuscitation fluid used in the intensive care unit (ICU). ${ }^{1,2}$ Nevertheless, the high chloride content has been shown to contribute to acid-base disturbances and acute kidney injury (AKI). ${ }^{3,4}$ Early experimental data suggest that hyperchloremia may lead to renal vasoconstriction and a decreased glomerular filtration rate. ${ }^{5,6}$ In a double-blind randomized study of healthy volunteers, intravenous infusion of NS, but not a buffered crystalloid infusion, resulted in decreased renal cortical perfusion. ${ }^{7}$ The clinical impact of high-chloride fluids on kidney function or other outcomes in critically ill or perioperative patients, however, remains a topic of debate. $^{8-10}$ Three large clinical trials comparing buffered crystalloid solution with NS infusion in the ICU have produced contradictory results with regard to the influence of fluid selection on renal function. ${ }^{11-13}$

Kidney transplant recipients are at particularly high risk of postoperative AKI and renal replacement therapy (RRT). Delayed graft function (DGF), defined as the need for RRT within the first week after transplantation, occurs in about $25-30 \%$ of deceased-donor transplants and is associated with higher costs, prolonged hospitalizations, and an increased risk of long-term graft loss. ${ }^{14,15}$ Transplant recipients often receive aggressive fluid resuscitation in an effort to reduce the incidence of DGF. ${ }^{16-18}$ Normal saline is usually the first choice of fluid in these patients, to avoid the potassium in buffered crystalloids such as Ringer's lactate, and the renal toxicity of synthetic colloids. ${ }^{19,20}$ The currently available data on the impact of perioperative NS resuscitation on renal graft function remain inconclusive. ${ }^{21}$ Most of the available studies focused on the intraoperative period, enrolled mainly living donors, or chose as the main endpoint either postoperative metabolic profile or non-standard definitions of DGF. ${ }^{22-28}$ Therefore, the aim of our study was to evaluate the impact of intraoperative and postoperative NS administration on graft function after kidney transplantation. 


\section{Methods}

We performed a retrospective study based on data prospectively collected in the CRISTAL database. The CRISTAL database was approved by the French Data Protection Authority (Authorization no. 363505). In accordance with French law, research studies based on the national registry CRISTAL are part of the transplant assessment activity and therefore do not require institutional review board approval or written informed consent.

This study adhered to the Strengthening the Reporting of Observational Studies in Epidemiology guidelines. ${ }^{29}$ The primary outcome was defined and the statistical analysis plan was made before accessing the data.

\section{Fluid management}

Our institutional protocol recommended NS as the primary appropriate intravenous fluid for the perioperative resuscitation of kidney transplant patients. Artificial colloid and potassium-containing balanced crystalloids were discouraged. All patients at our institution are admitted to our level-3 ICU following kidney transplantation, and the majority are discharged to the hospital floor $24 \mathrm{hr}$ postoperatively. According to our protocol, fluid infusion was considered if clinically indicated (systolic arterial pressure $<90 \mathrm{mmHg}$, tachycardia, cutaneous vasoconstriction, or relative oliguria) and the central venous pressure was $<5 \mathrm{mmHg}$.

\section{Data collection}

CRISTAL is a national database administered by the French transplant authority "Agence de la biomédecine" (ABM). Data of all organ transplant candidates, donors, and transplant outcomes are prospectively collected. The data collection is mandatory. Completeness and accuracy are double-checked by the ABM research technicians. Additional data were extracted retrospectively by chart review. All adult patients undergoing deceaseddonor kidney transplantation between January 12010 and December 32014 at the Rennes University Hospital (Brittany, France) were included.

\section{Donor-specific data}

The following kidney donor parameters were assessed: age and body mass index (BMI), cause of brain death, treatment with catecholamines in the perioperative period, and terminal serum creatinine.
Recipient-specific data

The following recipient parameters were assessed: recipient age, sex and BMI, graft cold ischemic time, and multiple organ transplantation. We recorded the volume of NS administered intraoperatively, and within the postoperative ICU period. We noted the use of any nonsaline fluid for resuscitation, and recorded the serum levels of sodium, potassium, chloride, and bicarbonate on postoperative day 0 and day 1 . Finally, we recorded the need for any RRT within the first postoperative week, and mortality at one year.

\section{Study outcomes}

The primary outcome was DGF, defined as the need for any RRT within one week after transplantation. An additional outcome was the fall in ratio of postoperative creatinine of at least $30 \%$, an alternative creatinine-based definition of DGF. $^{30,31}$ The creatinine reduction ratio (CRR) was calculated as follows: $\mathrm{CRR}=($ day 0 creatinine - day 1 creatinine/day 0 creatinine) $\mathrm{x} 100$.

Study definitions

Hyperchloremia was defined as serum chloride $>110$ $\mathrm{mmol} \cdot \mathrm{L}^{-1}$ within the first $24 \mathrm{hr}$ postoperatively, hyperchloremic acidosis was defined as serum chloride $>$ $110 \mathrm{mmol} \cdot \mathrm{L}^{-1}$ and serum bicarbonate $<24 \mathrm{mmol} \cdot \mathrm{L}^{-1}$ within the first $24 \mathrm{hr}$ postoperatively.

According to the Stewart's physical-chemical approach, strong ion difference (SID) may better reflect the acidifying effects of large volumes of saline compared with direct measurement of serum chloride or bicarbonate. ${ }^{32}$ Therefore, abbreviated SID was also calculated as SID = $\mathrm{Na}^{+}-\mathrm{Cl}^{-}$. SID Acidosis was defined by a SID $<40$ within the first $24 \mathrm{hr}$ postoperatively.

Statistical analysis

Continuous data were expressed as the mean (standard deviation [SD]) and compared by a Student's $t$ test or a Wilcoxon rank sum test. Categorical data were expressed as numbers and percentages and compared by a $\chi^{2}$ test or a Fisher's exact test. A Wilcoxon test was used to compare total saline infusion according to the pre-specified groups.

The relationship between DGF (dependent variable), hyperchloremic acidosis, hyperchloremia, and the SID were studied using three separate logistic regression models adjusted on potential confounders. Variables included as potential confounders were chosen a priori, and informed by the works of Schnuelle et al. ${ }^{33}$ and Irish et al. ${ }^{14}$ based on factors known to influence the risk of 
DGF. The first model included donor age, donor resuscitation with norepinephrine, donor terminal creatinine, cold ischemic time, recipient sex, recipient BMI, and hyperchloremic acidosis. The second model included the prior variables, with hyperchloremia in the place of hyperchloremic acidosis. The third model included the prior variables, with SID in the place of hyperchloremic acidosis. As a sensitivity analysis, the three models were then performed using an alternative definition of DGF $(\mathrm{CRR}<30 \%)$. Finally, as the association between hyperchloremic acidosis or hyperchloremia and DGF might reflect a fluid resuscitation effect with higher NS volumes rather than an effect of high chloride itself, we built multivariable models adjusted for total perioperative NS volume infused in addition to prior variables, as an additional sensitivity analysis.

As the rate of missing values was low $(<2 \%)$, with the exception of total NS volume (10\%), we used a single imputation method for the main analysis (mode for categorical variables and median for continuous variables) and multiple imputation methods for sensitivity analysis adjusted for total NS assuming a missing at random assumption.

A $P$ value of $<0.05$ for a two-sided test was considered statistically significant. Outputs of the logistic regression models were presented as the adjusted odds ratio (OR) and its $95 \%$ confidence interval (CI). Statistical analysis was performed using SAS statistical software (SAS 9.3, SAS Institute, Cary, NC, USA).

\section{Results}

Three hundred and fifty-nine patients were included, of whom 70 (20\%) developed DGF. The mean (SD) volume of saline infused in the $\mathrm{OR}$, and in the standard postoperative ICU stay was 4,832 (2,242) $\mathrm{mL}$. Postoperatively, $11 \%$ of patients developed hyperchloremia, $11 \%$ developed hyperchloremic acidosis, and $91 \%$ developed a SID $<40$ within the first $24 \mathrm{hr}$. Recipient and donor characteristics are displayed in Tables 1 and 2 respectively.

Patients who developed DGF received significantly higher NS volumes in the study period that those who did not $[n=64$ vs 261; mean (SD) total volume, 5,240 $(2,126) \mathrm{mL}$ vs $4,731(2,263) \mathrm{mL}$, respectively; difference in means, 509; 95\% CI, 8 to $765 ; P=0.03$ ]. Conversely, patients who developed hyperchloremic acidosis or hyperchloremia did not receive significantly higher volumes of NS than those who did not $[n=37$ vs 288; mean (SD) total volume, 5,543 $(2,234) \mathrm{mL} v s$ 4,740 $(2,230)$ $\mathrm{mL}$; difference in means, $802 \mathrm{~mL}$; $95 \% \mathrm{CI},-1$ to $1606 ; P=$ 0.06 ; and $n=38$ vs 287; total volume, 5,543 (2,234) vs
4,744 (2,234) $\mathrm{mL}$; difference in means, $798 \mathrm{~mL}$; 95\% CI, 5 to $1602 ; P=0.09$, respectively]. There was also no difference in NS volume infused between patients who developed hyperkalemia $\left(>6 \mathrm{mmol} \cdot \mathrm{L}^{-1}\right)$ and those who did not ( $n=26$ vs 296; mean (SD) total volume, 4,776 $(2,248)$ vs $5,398(2,211) \mathrm{mL}$, difference in means, $621 \mathrm{~mL}$; 95\% CI, -279 to $1522 ; P=0.18)$.

Upon multivariable analysis, recipient cold ischemic time (per ten-minute increase) and donor terminal creatinine level (per $10-\mu \mathrm{mol} \cdot \mathrm{L}^{-1}$ increase) were independent risk factors for DGF (Tables 3, 4, and 5). There was no significant relationship between hyperchloremic acidosis, hyperchloremia, or a SID $<40$ and DGF.

One-hundred and fifty-three (43\%) patients developed a CRR $<30 \%$. In the multivariable analysis (eTables 1, 2, and 3, available as Electronic Supplementary Material [ESM]), BMI (per $1 \mathrm{~kg} \cdot \mathrm{m}^{-2}$ increase), donor age (per-oneyear increase), and donor terminal creatinine level were independent risk factors for $\mathrm{CRR}<30 \%$. Again, there was no significant relationship between hyperchloremic acidosis, hyperchloremia, or a SID $<40$ and CRR $<30 \%$.

Adjusting the model for the total volume of NS infused did not significantly alter the relationship between hyperchloremic acidosis or hyperchloremia and DGF, but did show that total NS volume infused was significantly associated with DGF (Tables 6 and 7, and eTables 1, 2, and 3, available as ESM).

\section{Discussion}

In this cohort of patients undergoing deceased-donor kidney transplantation and resuscitated with NS, patients received large volumes of NS in the perioperative period. Only $11 \%$ of the patients developed hyperchloremia or hyperchloremic acidosis, but the majority of patients developed a SID $<40$. Nevertheless, neither the development of hyperchloremia or hyperchloremic acidosis, nor a SID $<40$ were associated with an increased risk of DGF.

Perioperative intravenous infusion of chloride-rich fluids has been associated with hyperchloremia and hyperchloremic acidosis in numerous studies. ${ }^{34}$ The supraphysiologic chloride content leads to an increase in the dominant strong anion in plasma, which in turn promotes an increase in hydrogen, and thus acidosis. Animal and human experimental data seems to support a potential chloride-related renal toxicity. Chloride influx in the afferent artery may cause vasoconstriction, decreasing the renal blood flow and glomerular filtration rate. ${ }^{5,7}$

In our study, patients who developed hyperchloremic acidosis or hyperchloremia had not received higher 
Table 1 Characteristics of the organ recipients

\begin{tabular}{|c|c|c|c|c|}
\hline & \multirow{2}{*}{$\begin{array}{l}\text { All patients } \\
n=359\end{array}$} & \multicolumn{2}{|c|}{ Delayed graft function } & \multirow[t]{2}{*}{$P$ value } \\
\hline & & Yes $n=70$ & No $n=289$ & \\
\hline Age (yr) & $52(14)$ & $54(13)$ & $52(15)$ & 0.37 \\
\hline Sex (male) & $208(58 \%)$ & $42(60 \%)$ & $166(57 \%)$ & 0.69 \\
\hline $\mathrm{BMI}\left(\mathrm{kg} \cdot \mathrm{m}^{-2}\right)$ & $25(5)$ & $26(6)$ & $25(4)$ & 0.27 \\
\hline Saline infused in the OR $(\mathrm{mL}) n=341$ & $2,058(1,007)$ & $2,397(1,236)$ & $2,058(932)$ & 0.19 \\
\hline Total saline infused, OR and ICU (mL) $n=325$ & $4,832(2,242)$ & $5,240(2,126)$ & $4,732(2,263)$ & 0.03 \\
\hline \multicolumn{5}{|l|}{ Other fluids infused $n=341$} \\
\hline Albumin & $10(3 \%)$ & $3(4 \%)$ & $7(2 \%)$ & 0.42 \\
\hline Gelatin & $36(10 \%)$ & $12(17 \%)$ & $24(8 \%)$ & 0.04 \\
\hline HES & $38(11 \%)$ & $8(11 \%)$ & $30(10 \%)$ & 0.83 \\
\hline Buffered crystalloids & $31(9 \%)$ & $11(16 \%)$ & $20(7 \%)$ & 0.03 \\
\hline Cold ischemic time $(\min ) n=358$ & $1,031(362)$ & $1,125(368)$ & $1,007(358)$ & 0.001 \\
\hline \multicolumn{5}{|l|}{ Serum chloride $\left(\mathrm{mmol} \cdot \mathrm{L}^{-1}\right)$} \\
\hline Day $0 n=357$ & $103(5)$ & $103(4)$ & $104(5)$ & 0.18 \\
\hline Day $1 n=357$ & $104(5)$ & $102(5)$ & $104(5)$ & 0.003 \\
\hline Hyperchloremic acidosis (within the first $24 \mathrm{hr}$ ) $n=358$ & $38(11 \%)$ & $4(6 \%)$ & $34(12 \%)$ & 0.14 \\
\hline Hyperchloremia $(>110 \mathrm{mmol} / \mathrm{L}$ within the first $24 \mathrm{hr}) n=357$ & $38(11 \%)$ & $4(6 \%)$ & $34(12 \%)$ & 0.14 \\
\hline \multicolumn{5}{|l|}{ SID } \\
\hline Day 0 & $34(4)$ & $34(4)$ & $36(4)$ & 0.01 \\
\hline Day 1 & $33(4)$ & $33(4)$ & $35(5)$ & 0.001 \\
\hline SID $<40$ (within the first $24 \mathrm{hr}$ ) & $328(91 \%)$ & $60(86 \%)$ & $268(93 \%)$ & 0.06 \\
\hline Hyperkalemia $>6 \mathrm{mmol} \cdot \mathrm{L}^{-1}$ & $29(8 \%)$ & $20(29 \%)$ & $9(3 \%)$ & 0.001 \\
\hline \multicolumn{5}{|l|}{ Multiple organ transplants } \\
\hline Kidney/liver & $11(3 \%)$ & $4(6 \%)$ & $7(2 \%)$ & 0.24 \\
\hline Heart/liver & $2(3 \%)$ & $1(1 \%)$ & $1(0.4 \%)$ & 0.35 \\
\hline One-year mortality & $14(4 \%)$ & $3(4 \%)$ & $11(4 \%)$ & 0.74 \\
\hline
\end{tabular}

Results are presented as $n(\%)$ or mean (SD). $n$ apart from the header row indicates the number of patients without missing data for the variable. $\mathrm{BMI}=$ body mass index; HES = hydroxyethyl starch; ICU = intensive care unit; OR = operating room; SID = strong ion difference.

volumes of NS than those who did not suggesting that NS administration might not be the only cause of hyperchloremic acidosis or hyperchloremia. Interestingly, after adjustment, increased total volume of NS received was associated with increased odds of DGF, whereas hyperchloremic acidosis or hyperchloremia were not. This observation might reflect a more aggressive fluid resuscitation in patients with early oliguria who subsequently will develop DGF. Conversely, fluid overload might result in increased venous pressure and kidney congestion, which lead to renal subcapsular pressure increase and reduced renal blood flow and glomerular filtration rate. ${ }^{35}$ Although, the recent Restrictive versus Liberal Fluid Therapy for Major Abdominal Surgery (RELIEF) trial found a significantly higher risk of kidney injury in the restrictive group, others observed a U-shaped distribution of risk associated with intravenous fluid dosing during non-cardiac surgery. ${ }^{36,37}$ Indeed, in the latter work, the risk for postoperative AKI was lowest in a moderately liberal group but was increased with both restrictive and liberal fluid practices. ${ }^{37}$ Similarly, a single-centre retrospective case series involving 1,966 kidney transplants on a 29 -year period found that volume administration $\geq 2,500 \mathrm{~mL}$ was an independent risk factor of graft failure. ${ }^{\overline{3} 8}$

The question of whether saline-induced hyperchloremia or hyperchloremic acidosis result in clinically significant renal toxicity remains controversial. NS and other chloriderich fluids have been associated with impaired renal function after liver transplantation or open abdominal surgery but not after cardiac surgery or emergent laparotomy with temporal abdominal closure. ${ }^{3,39-41}$ Noncardiac, non-transplant surgical patients with postoperative hyperchloremia are more likely to have postoperative renal dysfunction. ${ }^{42}$ Nevertheless, a 2017 Cochrane review concluded that there was insufficient evidence to show a difference between perioperative administration of buffered versus non-buffered crystalloid fluids on renal 
Table 2 Characteristics of the organ donors

\begin{tabular}{|c|c|c|c|c|}
\hline & \multirow{2}{*}{$\begin{array}{l}\text { All patients } \\
n=359\end{array}$} & \multicolumn{2}{|c|}{ Delayed graft function } & \multirow[t]{2}{*}{$P$ value } \\
\hline & & Yes $n=70$ & No $n=289$ & \\
\hline Age (yr) & $52(16)$ & $55(13)$ & $51(16)$ & 0.04 \\
\hline $\mathrm{BMI}\left(\mathrm{kg} \cdot \mathrm{m}^{-2}\right)$ & $26(5)$ & $27(6)$ & $25(5)$ & 0.06 \\
\hline Cause of brain death & & & & - \\
\hline Vascular & $194(54 \%)$ & $35(50 \%)$ & $159(55 \%)$ & \\
\hline Trauma & $109(30 \%)$ & $21(30 \%)$ & $88(30 \%)$ & \\
\hline Anoxia & $51(14 \%)$ & $14(20 \%)$ & $37(13 \%)$ & \\
\hline Other & $5(1 \%)$ & 0 & $5(2 \%)$ & \\
\hline \multicolumn{5}{|l|}{ Amines infusion $n=357$} \\
\hline Norepinephrine & $318(90 \%)$ & $64(93 \%)$ & $254(89 \%)$ & 0.53 \\
\hline Epinephrine & $8(3 \%)$ & $40(4 \%)$ & $4(2 \%)$ & 0.05 \\
\hline Dobutamine & $10(4 \%)$ & $5(7 \%)$ & $5(2 \%)$ & 0.03 \\
\hline Terminal creatinine $\left(\mu \mathrm{mol} \cdot \mathrm{L}^{-1}\right)$ & $138(92)$ & $201(177)$ & $123(38)$ & 0.001 \\
\hline
\end{tabular}

Results are presented as $n(\%)$ or mean (SD). BMI = body mass index.

Table 3 Factors associated with delayed graft function according to the multivariable analysis (logistic regression model including hyperchloremic acidosis)

\begin{tabular}{llr}
\hline Variable & Adjusted odds ratio & $95 \%$ CI \\
\hline Recipient sex (male) & 1.08 & 0.62 to 1.88 \\
Recipient BMI (per 1 kg.m ${ }^{-2}$ increase) & 1.03 & 0.97 to 1.09 \\
Norepinephrine use in recipient resuscitation (yes) & 1.44 & 0.53 to 3.92 \\
Donor age (per 1-year increase) & 1.02 & 0.99 to 1.03 \\
Donor terminal creatinine level (per 10- $\mu \mathrm{mol} \cdot \mathrm{L}^{-1}$ increase) & 1.07 & 1.01 to 1.13 \\
Cold ischemic time (per 10-min increase) & 1.01 & 1.00 to 1.02 \\
Hyperchloremic acidosis & 0.59 & 0.20 to 1.79
\end{tabular}

$\mathrm{BMI}=$ body mass index; $\mathrm{CI}=$ confidence interval.

Table 4 Factors associated with delayed graft function according to the multivariable analysis (logistic regression model including hyperchloremia)

\begin{tabular}{llr}
\hline Variable & Adjusted odds ratio & $95 \%$ CI \\
\hline Recipient sex (male) & 1.07 & 0.61 to 1.86 \\
Recipient BMI (per 1 $\mathrm{kg} \cdot \mathrm{m}^{-2}$ increase) & 1.03 & 0.97 to 1.09 \\
Norepinephrine use in recipient resuscitation (yes) & 1.44 & 0.53 to 3.93 \\
Donor age (per 1-year increase) & 1.02 & 0.99 to 1.03 \\
Donor terminal creatinine level (per 10- $\mu \mathrm{mol} \cdot \mathrm{L}^{-1}$ increase) & 1.07 & 1.01 to 1.13 \\
Cold ischemic time (per 10-min increase) & 1.01 & 1.00 to 1.02 \\
Hyperchloremia & 0.59 & 0.19 to 1.78 \\
\hline
\end{tabular}

$\mathrm{BMI}=$ body mass index; $\mathrm{CI}=$ confidence interval. 
Table 5 Factors associated with delayed graft function according to the multivariable analysis (logistic regression model including SID $<40$ )

\begin{tabular}{lll}
\hline Variable & Adjusted odds ratio & $95 \%$ CI \\
\hline Recipient sex (male) & 1.10 & 0.63 to 1.92 \\
Recipient BMI (per 1 kg.m ${ }^{-2}$ increase) & 1.03 & 0.97 to 1.09 \\
Norepinephrine use in recipient resuscitation (yes) & 1.45 & 0.53 to 3.95 \\
Donor age (per 1-year increase) & 1.02 & 1.00 to 1.04 \\
Donor terminal creatinine level (per 10- $\mu \mathrm{mol} \cdot \mathrm{L}^{-1}$ increase) & 1.07 & 1.01 to 1.13 \\
Cold ischemic time (per 10-min increase) & 1.01 & 1.00 to 1.02 \\
SID $<40$ & 0.52 & 0.22 to 1.2
\end{tabular}

$\mathrm{BMI}=$ body mass index; $\mathrm{CI}=$ confidence interval; SID = strong ion difference.

Table 6 Factors associated with delayed graft function according to the multivariable analysis (logistic regression model including hyperchloremic acidosis and total saline volume infused)

\begin{tabular}{lll}
\hline Variable & Adjusted odds ratio & $95 \%$ CI \\
\hline Recipient sex (male) & 0.97 & 0.55 to 1.72 \\
Recipient BMI (per 1 kg.m ${ }^{-2}$ increase) & 1.04 & 0.98 to 1.10 \\
Norepinephrine use in recipient resuscitation (yes) & 1.49 & 0.54 to 4.08 \\
Donor age (per 1-year increase) & 1.02 & 1.00 to 1.04 \\
Donor terminal creatinine level (per 10- $\mu$ mol $\cdot \mathrm{L}^{-1}$ increase) & 1.07 & 1.01 to 1.13 \\
Cold ischemic time (per 10-min increase) & 1.01 & 1.00 to 1.02 \\
Total saline volume infused (per 1-L increase) & 1.14 & 0.19 \\
Hyperchloremic acidosis & 0.52 & 0.00 to 1.29 \\
\hline
\end{tabular}

$\mathrm{BMI}=$ body mass index; $\mathrm{CI}=$ confidence interval.

Table 7 Factors associated with delayed graft function according to the multivariable analysis (logistic regression model including hyperchloremia and total saline volume infused)

\begin{tabular}{llr}
\hline Variable & Adjusted odds ratio & $95 \%$ CI \\
\hline Recipient sex (male) & 0.97 & 0.55 to 1.70 \\
Recipient BMI (per 1 kg.m ${ }^{-2}$ increase) & 1.04 & 0.98 to 1.10 \\
Norepinephrine use in recipient resuscitation (yes) & 1.50 & 0.55 to 4.10 \\
Donor age (per 1-year increase) & 1.02 & 1.00 to 1.04 \\
Donor terminal creatinine level (per 10- $\mu$ mol $\cdot \mathrm{L}^{-1}$ increase) & 1.07 & 1.01 to 1.13 \\
Cold ischemic time (per 10-min increase) & 1.01 & 1.00 to 1.02 \\
Total saline volume infused (per 1-L increase) & 1.14 & 0.20 \\
Hyperchloremia & 0.52 & 0.09 to 1.29 \\
\hline
\end{tabular}

$\mathrm{BMI}=$ body mass index; $\mathrm{CI}=$ confidence interval.

function. ${ }^{43}$ Two clinical trials comparing NS and balanced crystalloids in critically ill medical and surgical patients came to opposite conclusions regarding the impact on renal function. One found that the risk of AKI was not reduced whether NS or balanced solutions was used, the other found a decrease in a composite outcome of death from any cause, new RRT, or persistent renal dysfunction with the use of a balanced solution rather than NS. ${ }^{12,13}$

With respect to kidney transplantation, seven randomized trials comparing NS and balanced solutions have attempted to address this question. ${ }^{22-28}$ Nevertheless, five of the studies included more than 90\% living donor kidney transplant recipients, who typically have a much lower risk of DGF. One study enrolled 150 patients, but sample sizes were often low with fewer than 90 patients. Only one study evaluated kidney graft function as the main endpoint represented by the plasma creatinine concentration on postoperative day 3 and no differences were found between groups. ${ }^{22}$ The other studies evaluated acid-base disturbances or 
occurrence of hyperkalemia as the main endpoints. Four studies reported DGF as the need for RRT in the first week after transplantation, without showing significant differences between groups, but all were underpowered to draw conclusions regarding that endpoint. ${ }^{23-25,28}$ While lower $\mathrm{pH}$ or bicarbonate and higher chloride concentrations were consistently observed in saline groups, only two studies reported significantly more hyperkalemia in the NS group. $^{22,24}$ Of note, the proportion of patients with hyperkalemia $>6$ $\mathrm{mmol} \cdot \mathrm{L}^{-1}$ in the Weinberg et al. study was far higher than in ours, including $25 \%$ in the patients treated with Plasma-Lyte $\odot$ and $60 \%$ in the NS group. In contrast, O'Malley et al., reported that only patients in the NS group developed hyperkalemia (19\%). Importantly, O'Malley et al. evaluated patients only intraoperatively. Finally, a Cochrane systematic review which included six of the seven trials confirmed the association of NS use with hyperchloremic acidosis but was unable to reach a conclusion regarding the impact of NS on graft function compared with balanced solutions. $^{21}$

Our study has several strengths. First, unlike most prior studies we chose DGF rather than acid-base status as the primary outcome. We also used the standard definition of DGF (need for RRT in the first postoperative week). ${ }^{30} \mathrm{In}$ our work, the rate of DGF was $20 \%$, similar to the rates recently reported in the US. ${ }^{44,45}$ Second, the risk factors associated with DGF or CRR $<30 \%$ found in our study (donor BMI, donor terminal serum creatinine value, donor age, and cold ischemic time) were congruent with the risk factors previously identified associated with DGF underlying the consistency of our cohort. ${ }^{14,46}$ Third, results were confirmed in sensitivity analysis using a creatinine-based definition of DGF. Finally, the sample size is also notable given the lower sample size of the previous trials available on the topic. Our study also has several limitations that warrant discussion. The retrospective design limits our insight into why patients received the fluid volumes that they did. The single-centre nature of the study may also limit the generalizability of the results. Although potential confounders chosen were factors known to influence the risk of DGF according to the literature, all observational studies have some degree of residual confounding.

In conclusion, our data showed that perioperative NS infusion volume was associated with an increased risk of DGF in deceased-donor kidney transplant recipients. Conversely, hyperchloremia and hyperchloremic acidosis were not associated with an increased risk of DGF, suggesting other mechanisms than a chloride effect.
Author contributions Nicolas Nesseler, Alexandre Rached, and Ronan Garlantezec contributed to the study concept and design. Nicolas Nesseler, Alexandre Rached, James T. Ross, and Ronan Garlantezec contributed to the acquisition, analysis, or interpretation of data. $R G$ performed the statistical analysis. Nicolas Nesseler, Alexandre Rached, James T. Ross, Yoann Launey, Ronan Garlantezec, and Yannick Mallédant drafted the manuscript, which was revised for important intellectual content by Karim Bensalah, Cécile Vigneau, Hélène Beloeil, and Yoann Launey.

Acknowledgements We would like to thank for their assistance the research technicians from the Agence de la Biomédecine in Rennes, France.

\section{Competing interests None.}

Funding statement None.

Editorial responsibility This submission was handled by Dr. Philip M. Jones, Associate Editor, Canadian Journal of Anesthesia.

\section{References}

1. Finfer $S$, Liu B, Taylor C, et al. Resuscitation fluid use in critically ill adults: an international cross-sectional study in 391 intensive care units. Crit Care 2010. DOI:https://doi.org/10.1186/ cc9293.

2. Hammond NE, Taylor C, Finfer S, et al. Patterns of intravenous fluid resuscitation use in adult intensive care patients between 2007 and 2014: an international cross-sectional study. PLoS One 2017. DOI:https://doi.org/10.1371/journal.pone.0176292.

3. Shaw AD, Bagshaw SM, Goldstein SL, et al. Major complications, mortality, and resource utilization after open abdominal surgery: 0.9\% saline compared to Plasma-Lyte. Ann Surg 2012; 255: 821-9.

4. Yunos NM, Bellomo R, Hegarty C, Story D, Ho L, Bailey M. Association between a chloride-liberal vs chloride-restrictive intravenous fluid administration strategy and kidney injury in critically ill adults. JAMA 2012; 308: 1566-72.

5. Wilcox CS. Regulation of renal blood flow by plasma chloride. $\mathrm{J}$ Clin Invest 1983; 71: 726-35.

6. Bullivant EM, Wilcox $C S$, Welch WJ. Intrarenal vasoconstriction during hyperchloremia: role of thromboxane. Am J Physiol 1989; 256: F152-7.

7. Chowdhury AH, Cox EF, Francis ST, Lobo DN. A randomized, controlled, double-blind crossover study on the effects of 2-L infusions of $0.9 \%$ saline and Plasma-Lyte ${ }^{\circledR} 148$ on renal blood flow velocity and renal cortical tissue perfusion in healthy volunteers. Ann Surg 2012; 256: 18-24.

8. Krajewski ML, Raghunathan K, Paluszkiewicz SM, Schermer CR, Shaw $A D$. Meta-analysis of high- versus low-chloride content in perioperative and critical care fluid resuscitation. Br J Surg 2014; 102: 24-36.

9. Young $P$. Saline is the solution for crystalloid resuscitation. Crit Care Med 2016; 44: 1538-40.

10. Kawano-Dourado L, Zampieri FG, Azevedo LC, et al. Lowversus high-chloride content intravenous solutions for critically ill and perioperative adult patients: a systematic review and metaanalysis. Anesth Analg 2018; 126: 513-21.

11. Semler $M W$, Wanderer JP, Ehrenfeld JM, et al. Balanced crystalloids versus saline in the intensive care unit. The SALT 
randomized trial. Am J Respir Crit Care Med 2017; 195: 136272.

12. Semler $M W$, Self $W H$, Wanderer JP, et al. Balanced crystalloids versus saline in critically ill adults. N Engl J Med 2018; 378: 82939.

13. Young $P$, Bailey $M$, Beasley $R$, et al. Effect of a buffered crystalloid solution vs saline on acute kidney injury among patients in the intensive care unit: the SPLIT randomized clinical trial. JAMA 2015; 314: 1701-10.

14. Irish WD, Ilsley JN, Schnitzler MA, Feng S, Brennan DC. A risk prediction model for delayed graft function in the current era of deceased donor renal transplantation. Am J Transplant 2010; 10: 2279-86.

15. Yarlagadda SG, Coca SG, Formica RN Jr, Poggio ED, Parikh $C R$. Association between delayed graft function and allograft and patient survival: a systematic review and meta-analysis. Nephrol Dial Transplant 2008; 24: 1039-47.

16. De Gasperi A, Narcisi S, Mazza E, et al. Perioperative fluid management in kidney transplantation: is volume overload still mandatory for graft function? Transplant Proc 2006; 38: 807-9.

17. Bacchi G, Buscaroli A, Fusari $M$, et al. The influence of intraoperative central venous pressure on delayed graft function in renal transplantation: a single-center experience. Transplant Proc 2010; 42: 3387-91.

18. Zukowski M, Bohatyrewicz R, Krawczyk AA. Influence of selected factors on occurrence of delayed kidney graft function: a multivariate analysis. Transplant Proc 2007; 39: 2704-6.

19. O'Malley CM, Frumento RJ, Bennett-Guerrero E. Intravenous fluid therapy in renal transplant recipients: results of a US survey. Transplant Proc 2002; 34: 3142-5.

20. Schmid S, Jungwirth B. Anaesthesia for renal transplant surgery: an update. Eur J Anaesthesiol 2012; 29: 552-8.

21. Wan S, Roberts MA, Mount P. Normal saline versus lowerchloride solutions for kidney transplantation. Cochrane Database Syst Rev 2016; 107: 264-264.

22. O'Malley CM, Frumento RJ, Hardy MA, et al. A randomized, double-blind comparison of lactated Ringer's solution and $0.9 \%$ $\mathrm{NaCl}$ during renal transplantation. Anesth Analg 2005; 100: 1518-24.

23. Potura E, Lindner $G$, Biesenbach $P$, et al. An acetate-buffered balanced crystalloid versus $0.9 \%$ saline in patients with end-stage renal disease undergoing cadaveric renal transplantation: a prospective randomized controlled trial. Anesth Analg 2015; 120: 123-9.

24. Weinberg L, Harris L, Bellomo R, et al. Effects of intraoperative and early postoperative normal saline or Plasma-Lyte $148{ }^{\circledR}$ on hyperkalaemia in deceased donor renal transplantation: a doubleblind randomized trial. Br J Anaesth 2017. DOI:https://doi.org/ 10.1093/bja/aex163.

25. Kim SY, Huh KH, Lee JR, Kim SH, Jeong SH, Choi YS. Comparison of the effects of normal saline versus Plasmalyte on acid-base balance during living donor kidney transplantation using the Stewart and base excess methods. Transplant Proc 2013; 45: 2191-6.

26. Modi MP, Vora KS, Parikh GP, Shah VR. A comparative study of impact of infusion of Ringer's lactate solution versus normal saline on acid-base balance and serum electrolytes during live related renal transplantation. Saudi J Kidney Dis Transpl 2012; 23: 135-7.

27. Khajavi MR, Etezadi F, Moharari RS, et al. Effects of normal saline vs. lactated Ringer's during renal transplantation. Ren Fail 2009; 30: 535-9.

28. Hadimioglu N, Saadawy I, Saglam T, Ertug Z, Dinckan A. The effect of different crystalloid solutions on acid-base balance and early kidney function after kidney transplantation. Anesth Analg 2008; 107: 264-9.
29. von Elm E, Altman DG, Egger M, et al. Strengthening the Reporting of Observational Studies in Epidemiology (STROBE) statement: guidelines for reporting observational studies. BMJ 2007; 335: 806-8.

30. Mallon DH, Summers DM, Bradley JA, Pettigrew GJ. Defining delayed graft function after renal transplantation: simplest is best. Transplantation 2013; 96: 885-9.

31. Govani MV, Kwon O, Batiuk TD, Milgrom ML, Filo RS. Creatinine reduction ratio and 24-hour creatinine excretion on posttransplant day two: simple and objective tools to define graft function. J Am Soc Nephrol 2002; 13: 1645-9.

32. Morgan TJ, Venkatesh B, Hall J. Crystalloid strong ion difference determines metabolic acid-base change during in vitro hemodilution. Crit Care Med 2002; 30: 157-60.

33. Schnuelle P, Gottmann U, Hoeger S, et al. Effects of donor pretreatment with dopamine on graft function after kidney transplantation: a randomized controlled trial. JAMA 2009; 302: 1067-75.

34. Yunos NM, Bellomo R, Story D, Kellum J. Bench-to-bedside review: chloride in critical illness. Crit Care 2010. DOI:https:// doi.org/10.1186/cc9052.

35. Prowle JR, Kirwan CJ, Bellomo R. Fluid management for the prevention and attenuation of acute kidney injury. Nat Rev Nephrol 2014; 10: 37-47.

36. Myles PS, Bellomo R, Corcoran T, et al. Restrictive versus liberal fluid therapy for major abdominal surgery. N Engl J Med 2018; 378: 2263 74.

37. Shin CH, Long DR, McLean D, et al. Effects of intraoperative fluid management on postoperative outcomes: a hospital registry study. Ann Surg 2018; 267: 1084-92.

38. Campos L, Parada B, Furriel F, Castelo D, Moreira P, Mota A. Do intraoperative hemodynamic factors of the recipient influence renal graft function? Transplant Proc 2012; 44: 1800-3.

39. Loftus TJ, Efron PA, Bala TM, et al. Hypertonic saline resuscitation after emergent laparotomy and temporary abdominal closure. J Trauma Acute Care Surg 2018; 84: 350-7.

40. McIlroy D, Murphy D, Kasza J, Bhatia D, Wutzlhofer L, Marasco S. Effects of restricting perioperative use of intravenous chloride on kidney injury in patients undergoing cardiac surgery: the LICRA pragmatic controlled clinical trial. Intensive Care Med 2017; 43: 795806.

41. Nadeem A, Salahuddin N, El Hazmi A, et al. Chloride-liberal fluids are associated with acute kidney injury after liver transplantation. Crit Care 2014. DOI:https://doi.org/10.1186/s13054-014-0625-7.

42. McCluskey SA, Karkouti K, Wijeysundera D, Minkovich L, Tait G, Beattie WS. Hyperchloremia after noncardiac surgery is independently associated with increased morbidity and mortality: a propensity-matched cohort study. Anesth Analg 2013; 117: 412-21.

43. Bampoe S, Odor PM, Dushianthan A, et al. Perioperative administration of buffered versus non-buffered crystalloid intravenous fluid to improve outcomes following adult surgical procedures. Cochrane Database Syst Rev 2017. DOI:https://doi. org/10.1002/14651858.CD004089.pub3.

44. Taber DJ, DuBay D, McGillicuddy JW, et al. Impact of the new Kidney Allocation System on perioperative outcomes and costs in kidney transplantation. J Am Coll Surg 2017. DOI:https://doi.org/ 10.1016/j.jamcollsurg.2016.12.009.

45. Stewart DE, Kucheryavaya AY, Klassen DK, Turgeon NA, Formica RN, Aeder MI. Changes in deceased donor kidney transplantation one year after KAS implementation. Am J Transplant 2016; 16: 1834-47.

46. Siedlecki A, Irish $W$, Brennan DC. Delayed graft function in the kidney transplant. Am J Transplant 2011; 11: 2279-96.

Publisher's Note Springer Nature remains neutral with regard to jurisdictional claims in published maps and institutional affiliations. 